IJBPAS, November, 2020, 9(11): 3176-3186

ISSN: 2277-4998

International Journal of Biology, Pharmacy

and Allied Seiences (IJBPAS)

'A Bridge Betusen Caboratory and Q Qndor'

www.ibpas,com

DIOSCIN SUPPRESSED TGF-ß1 INDUCED EMT AND METASTATIC-RELATED BEHAVIORS OF MCF7 AND MDA-MB-231 BREAST CANCER CELLS

\title{
YOGARAJ SR ${ }^{1}$, PRABU KUMAR $S^{2}$ AND PREMKUMAR $\mathrm{K}^{1^{*}}$
}

1: Department of Biomedical Science, Bharathidasan University, Tiruchirappalli, Tamil Nadu, India620024

2: Department of Biotechnology, Bharathidasan University, Tiruchirappalli, Tamil Nadu, India-620024

*Corresponding Author: Kumpati Premkumar: E Mail: premslab@gmail.com; +91 431-240707/ Fax: 0431-2407045

Received 22 ${ }^{\text {nd }}$ March 2020; Revised $23^{\text {rd }}$ April 2020; Accepted $20^{\text {th }}$ May 2020; Available online $1^{\text {st }}$ Nov. 2020 https://doi.org/10.31032/IJBPAS/2020/9.11.5487

ABSTRACT

Breast cancer is the most commonly occurring cancer in women and the second most common cancer overall. Metastases are major cause for the Breast cancer associated deaths. Epithelial-toMesenchymal Transitions (EMT) attune the micro environment of tumors and are recognized in the progression of metastatic disease. This propagation of tumor cells from the primary site is the foremost challenge in cancer treatment as they are resistance to conservative therapies. Thus, investigation of effective drug targets against these cancer cells is necessary. The potential of Dioscin, a natural steroidal saponin on EMT induced MCF7 and MDA-MB-231 cells has not been explored. In the present study, we performed to elucidate the effectof Dioscin in modulating metastatic related behaviors of breast cancer cells. Transforming growth factor beta 1 (TGF- $\beta 1$ ) is used to induce EMT and promote breast cancer cell migration and invasion in vitro. Dioscin inhibited TGF- $\beta 1$ induced cell migration and invasion in MCF7 and MDA-MB-231 cells. Also, Dioscin significantly increased the expression of E-Cadherin and decreased the expression of N-Cadherin and Vimentin. Based on these results, Dioscin may be considered as a promising compound for the treatment of advanced Breast cancer cells.

Keywords: Breast cancer, Metastasis, Dioscin, Epithelial-to-Mesenchymal Transitions (EMT) and TGF-ß1 


\section{INTRODUCTION}

Cancer occurrence and mortality are mounting at a dynamic pace across the world. Breast cancer is the most commonly diagnosed among females in more than 150 countries [1]. In India, Breast cancer incidence rate was as high as 25.8 per 100,000 women and mortality accounting for 12.7 per 100,000 women making it leading disease in 2012 [2]. Metastasis, dissemination of cancer cells to distant sites is estimated as the main reason of $90 \%$ of cancer-related mortality due to its incurability by surgical resection and resistance of tumor cells to chemotherapeutic agents. The process from the spreading of cancer cells to distant parts of the body, termed as the invasion-metastasis cascade, involves sequential and interrelated steps: (a) invasion of local tissue, (b) intravasation into stroma and blood vessels, (c) survival in vasculature circulation, (d) extravasation into the parenchyma of distant tissues, and (e) survival in a new microenvironment and colonization to form micro- and macrometastasis [3].

Epithelial to Mesenchymal Transition (EMT) describes the processes that convert epithelial cells into mesenchymal cells. This happens through the loss of polarity and cell-cell adhesions in the epithelial cells, along with the onset of capabilities to migrate, proliferate, differentiate, and develop into specific tissues and organs. While their function and activity is not yet fully understood, research has shown that mesenchymal cells are key to tissue repair and pathological processes. During the transition process, cells can acquire molecular alterations that may support the development of dysfunctional junctions and adhesions between cells, and impact their morphology. Tumor invasiveness and metastasis are supported by both of these factors. EMT arises through following major steps during cancer development. First, Epithelial cells lose cell-cell junctions and its marker E-cadherin. Second, they gain mesenchymal marker $\mathrm{N}$-cadherin and vimentin. Third, it undergoes foremost alterations in cytoskeleton rearrangement which enables them to attain mesenchymal properties such as cell migratory and invasive characteristics. This multifunctional processis orchestrated by various EMTinducing transcription factors such as Snail, Slug, Twist, Zeb1, Zeb2, Foxc2, Prrx1, etc. [4]. Tumor cells with migratory and invasive behaviors are important elements affecting responses to conventional and targeted therapies. 
Dioscin is a typical natural product derived from some medicinal plants commonly used in Asia [5]. Pharmacological research has revealed that Dioscin has anti-inflammatory, lipid-lowering, anticancer, and hepatoprotective effects $[6,7]$. Anticancer effect of Dioscin on various cancer cells such as human lung cancer, human leukemia and hepatocellular carcinoma has been reported [8]. However, the effect of Dioscin on EMT induced breast cancer cells is still not clearly explored.

Transforming growth factor- $\beta 1$ (TGF- $\beta 1)$ induce EMT and stimulate the growth of a mesenchymal phenotype by increasing the expression of EMT markers and also the proliferation, invasion and migration of cells [9]. In the present study, we studied to reveal whether Dioscin could suppress TGF- $\beta 1$ induced EMT in Human breast cancer cells.

\section{MATERIALS AND METHODS}

\section{Drugs and Reagents}

Dioscin (SMB00576, $\geq 95 \%$ pure, SigmaAldrich, India), TGF- $\beta 1$ (8915, Cell Signaling Technology, USA), MTT formazan powder, DCFH-DA, Acridine Orange, EtBr were purchased from SigmaAldrich. All other chemical used in this study were of analytical grade.

\section{Cell culture}

Human breast adenocarcinoma cell lines MCF7 (ER+), MDA-MB-231 (ER-) were procured from National Centre for Cell Sciences, Pune, India, and maintained in DMEM (Himedia, India) under standard conditions in Eppendorf/New Brunswick Galaxy $\mathrm{CO} 2$ incubator. Exponentially growing cells with $80-90 \%$ confluency were harvested and used for experiments. EMT stimulation were done by treating cells with $5 \mathrm{ng} / \mathrm{mL}$ TGF- $\beta 1$ for $24 \mathrm{~h}$. Then, the Dioscin was added to the culture medium for experiments. Dioscin was dissolved in DMSO.

\section{Cell viability assay}

Breast Cancer cells were plated at a density of $1 \times 10^{4}$ cells/well on 96-well plate in $100 \mu \mathrm{L}$ medium. After $24 \mathrm{~h}$ incubation, the cells were treated with different concentrations of Dioscin (1 to $10 \mu \mathrm{M})$. Stock Concentration of Dioscin was prepared (1 $\mathrm{mg} / \mathrm{mL}$ ) which was then diluted 100-400 times in the culture medium before treatment. The inhibitory effects of Dioscin on the cancer cells were estimated by MTT assay.

\section{Dual staining}

The cancer cells were seeded in six-well plates and incubated overnight. After being treated with different concentrations of Dioscin $(5,7.5$ and $10 \mu \mathrm{M})$, the cells were washed twice with cold PBS, then the mixture containing same volume of AO (100 $\mu \mathrm{g} / \mathrm{mL}$ in PBS $)$ and $\mathrm{EB}(100 \mu \mathrm{g} / \mathrm{mL}$ in PBS $)$ 
was put onto the cells, and then the images of the cells were obtained by using an inverted fluorescence microscope (Eclipse80i, Nikon, Japan).

\section{Colony formation assay}

Cells were seeded on a 6-well plates at a density of 500 cells per well and then treated Dioscin for $4 \mathrm{~h}$. After being rinsed with fresh medium, cells were allowed to grow for 10 days to form colonies, which were then fixed with $4 \%$ paraformaldehyde for $30 \mathrm{mins}$ and stained by commasive blue. Colonies containing more than 50 cells were counted.

\section{Wound healing assay}

$\mathrm{BC}$ cells were seeded in 6 well plates at a density of $3 \times 10^{5}$ cells/well. After cell adhesion with EMT stimulation, a scratch was made using a $10 \mu \mathrm{L}$ tip at the center of the wells and the wound healing ability were assayed at different time points. Photographs were taken at different time intervals and analyzed using ImageJ software.

\section{Transwell migration assay}

The invasion of $\mathrm{BC}$ cells were measured according to the manufacturer's instruction with sterile transwell chambers. Total of $5 \times 10^{4}$ cells in serum-free medium $(200 \mu \mathrm{L})$ were added into the upper chambers while the lower chamber was filled with $500 \mu \mathrm{L}$ of medium containing $10 \%$ FBS. After incubation with Dioscin for $24 \mathrm{~h}$, the cells were fixed with $4 \%$ formaldehyde for $20 \mathrm{mins}$ and stained with hematoxylin for 20mins. The cells in five randomly selected fields were counted under an inverted phasecontrast microscope.

\section{RT-PCR analysis}

Total RNA extracted from experimental cells was converted to cDNA using a Gene Amp RNA-PCR kit (Applied Biosystems, CA, USA). The cDNAs were used for PCR analysis using oligonucleotide primers specific for E-cadherin (forward 5'TAAACTCCTGGCCTCAAGCA ATC-3' and reverse 5'TCCTATCTTGGGCAAAGCAACTG - 3'); $\mathrm{N}$-cadherin (forward 5'CGA ATGGATGAAAAGACCCATCC - 3' and reverse5'GGAGCCACTGCCTTCATCGTC AA-3'); vimentin (forward 5' TGAGTACCGGAGACAGGTGCAG-3' and reverse 5, - TAGCAGCTTCA ACGGCAAAGTTC-3'). The PCR was performed using Thermal Cycler Dice (TaKaRa, Otsu, Japan) under the following conditions: $95^{\circ} \mathrm{C}$ for $5 \mathrm{mins}, 50$ cycles of $95^{\circ} \mathrm{C}$ for $5 \mathrm{~s}$, and $60^{\circ} \mathrm{C}$ for $10 \mathrm{~s}$. The primers were purchased from TaKaRa and were used with SYBR Premix Ex Taq (TaKaRa). GAPDH was used as an internal control to normalize and compare each sample. 


\section{Statistical analysis}

All experiments were repeated at least three times. Data are expressed as mean \pm S.D. Two-way analysis of variance (ANOVA) and multiple comparisons were used to evaluate the statistical significance of difference between groups.

\section{RESULTS}

Dioscin inhibits proliferation of Breast cancer cells

Exposure of MCF7 and MDA-MB-231 cells to Dioscin (1 to $10 \mu \mathrm{M})$ for $24 \mathrm{~h}$ and $48 \mathrm{~h}$ time points showed a dose-dependent decrease in cell viability. The maximum dose $(10 \mu \mathrm{M})$ of Dioscin used for the study induced $74 \%$ and $78 \%$ cell death in both MCF7 and MDAMB-231 cells respectively at both timedurations ( $24 \mathrm{~h}$ and $48 \mathrm{~h}$ ). The increase in treatment duration showed no significant variation in cell viability. Based on this results, we found that Dioscin decreased the viability of MCF7 and MDA-MB-231 in a dose dependent manner with a half maximal inhibitory concentration $\left(\mathrm{IC}_{50}\right)$ of $7.5 \mu \mathrm{M}$ and $8 \mu \mathrm{M}$ respectively (Figure 1).

To differentiate live and dead cells based on their morphological features, treated and untreated cells were stained with $\mathrm{AO} / \mathrm{EB}$ and visualized using fluorescent microscopy. The untreated cells displayed green nuclei with an intact nuclear architecture while Dioscin treated cells (Figure 2 \& 3) displayed cell shrinkage, nuclear condensation. This result strongly demonstrates that the $\mathrm{IC}_{50}$ concentration has the ability to induce apoptosis in MCF7 and MDA-MB-231 cell lines. Because we aimed to examine the effects of Dioscin on metastasis of MCF7 and MDA-MB-231 cells, we selected the less cytotoxic concentrations of Dioscin (2, 4 and $6 \mu \mathrm{M})$ to treat both cells for subsequent experiments. Low concentration of Dioscin reversed the growth-promoting effect of TGF- $\beta 1$ on Breast cancer cells in a colony formation assay (Figure $4 \& 5$ ).

\section{Dioscin inhibits migration and invasion potential of TGF- $\beta 1$ induced BC cells}

The effect of Dioscin on the migratory potential of experimental cells was analyzed by the scratch assay. The scratch assay is a straightforward method to study cell migration in vitro. A uniform scratch was made in experimental cells with or without Dioscin. It was observed that Dioscin, slowed down the process of wound healing compared to the TGF- $\beta 1$ induced cells concentration dependently (Figure $6 \&$ 7).

Consistently, the transwell migration assay demonstrated that Dioscin treatment also inhibited the invasion of MCF7 and MDAMB-231 cells (Figure 8). These results suggested that Dioscin suppresses EMT 
through modulating the migration and invasion of TGF- $\beta 1$ induced Breast cancer cell lines.

\section{Dioscin alters expression of EMT markers} in TGF- $\beta 1$ induced $B C$ cells

The expression analysis of specific EMT marker E-cadherin (E-cad), N-cadherin $(\mathrm{N}$ - cad) and Vimentin was performed to confirm Dioscin effect on TGF- $\beta 1$ induced Breast cancer cells. Results showed a significant increase of $\mathrm{N}$-cadherin \& Vimentin and decrease of E-cadherin expression in TGF$\beta 1$ exposed cells and was reversed with Dioscin treatment (Figure 9).
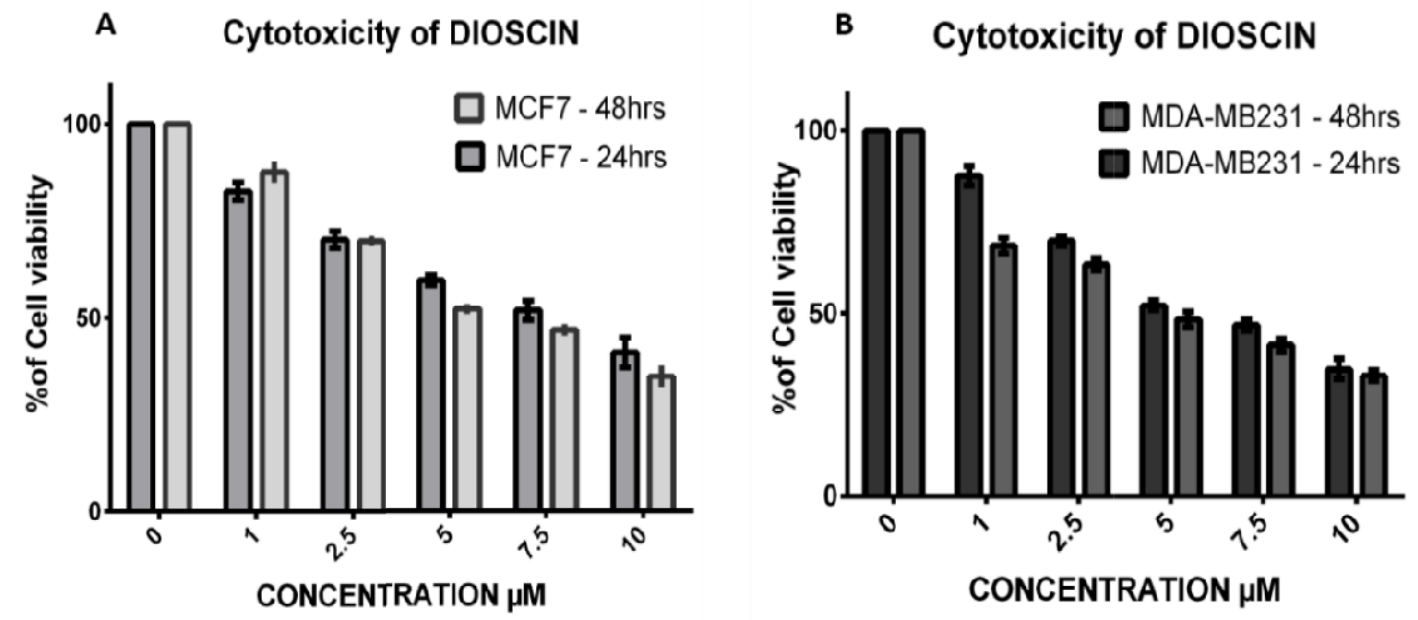

Figure 1: In vitro cytotoxicity effect ofDioscin on A) MCF7 and B) MDA-MB-231. Data expressed as mean \pm S.D. of three independent experiments

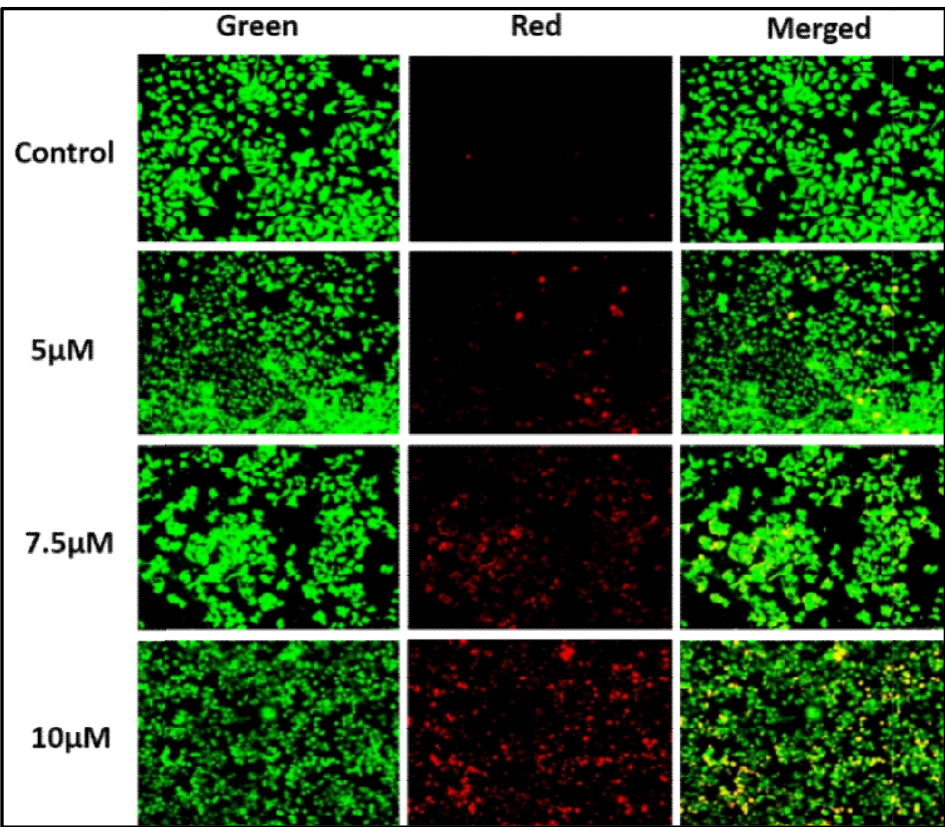

Figure 2: Fluorescent microscopic images ofMCF7 cells treated with Dioscin determined byAO/EB dual staining (Scale Bar 10X) 


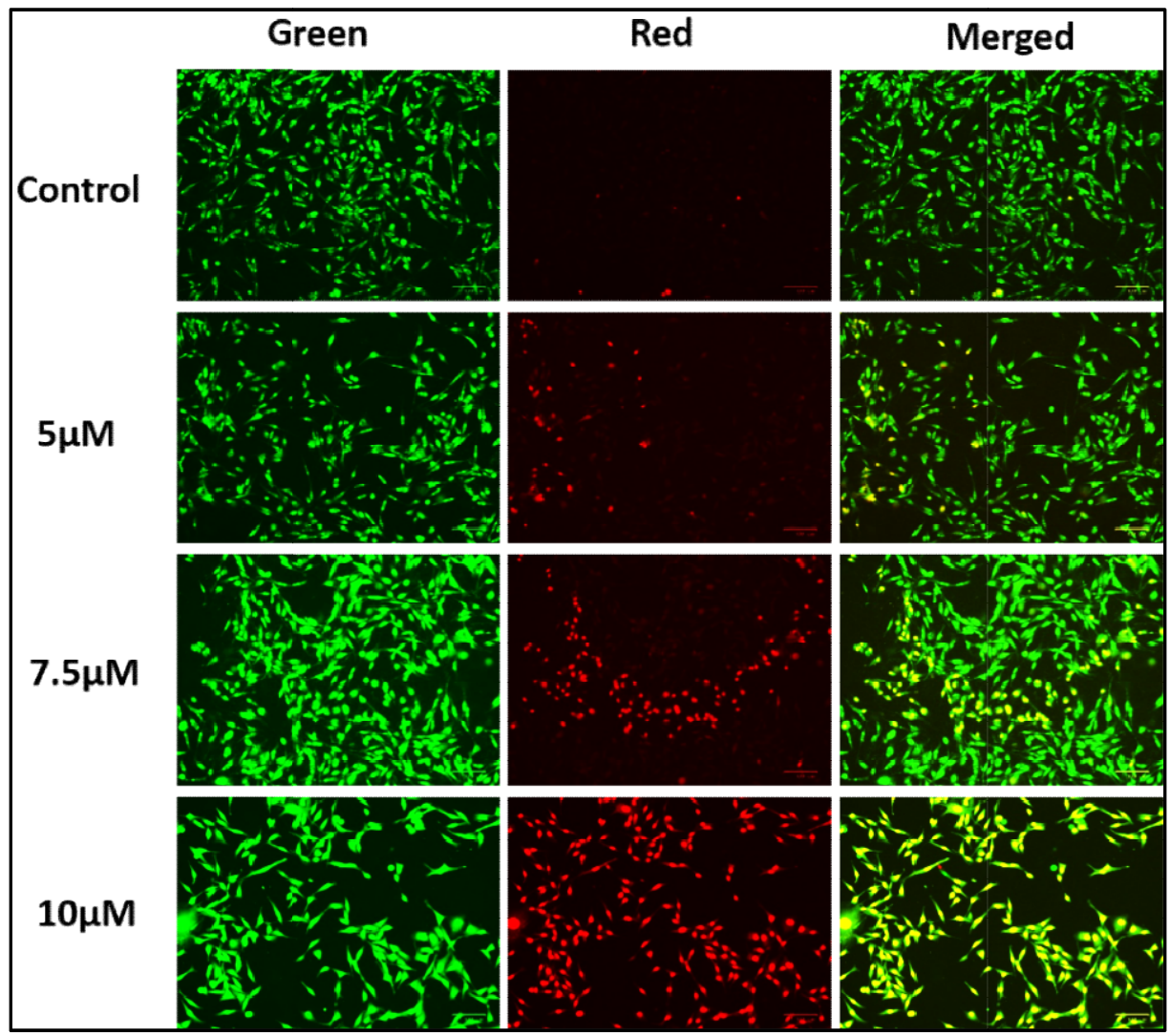

Figure 3: Fluorescent microscopic images of MDA-MB-231 cells treated with Dioscin determined by AO/EB dual staining (Scale Bar 10X)

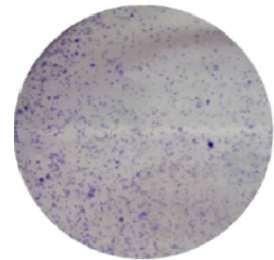

Control

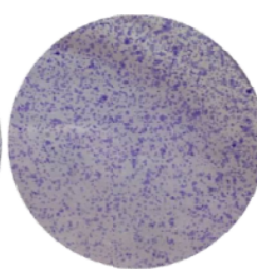

TGFb1

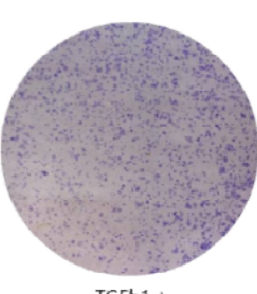

Dioscin $(2 \mu \mathrm{M})$

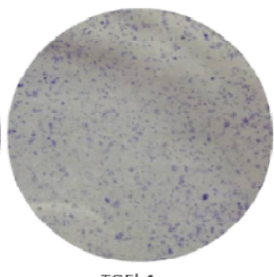

TGFb1 +

Dioscin $(4 \mu \mathrm{M})$

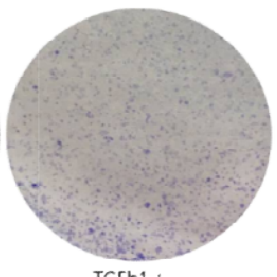

TGFb1 $1+$ Dioscin $(6 \mu \mathrm{M})$

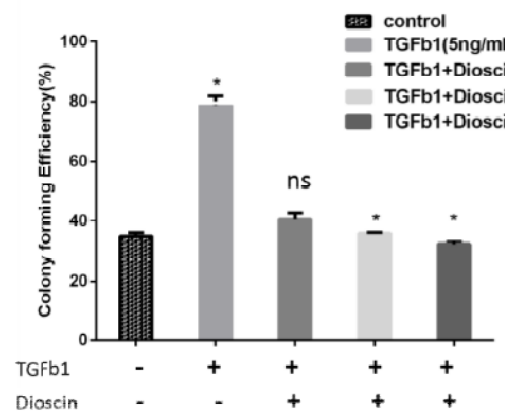

Figure 4: Invitro colony formation assay. Effect of Dioscin on MCF7 cells with TGF- $\beta 1$ stimulation; *p<0.05, **p<0.001, $* * * \mathbf{p}<0.001$, NS-Non-significant compared to control 

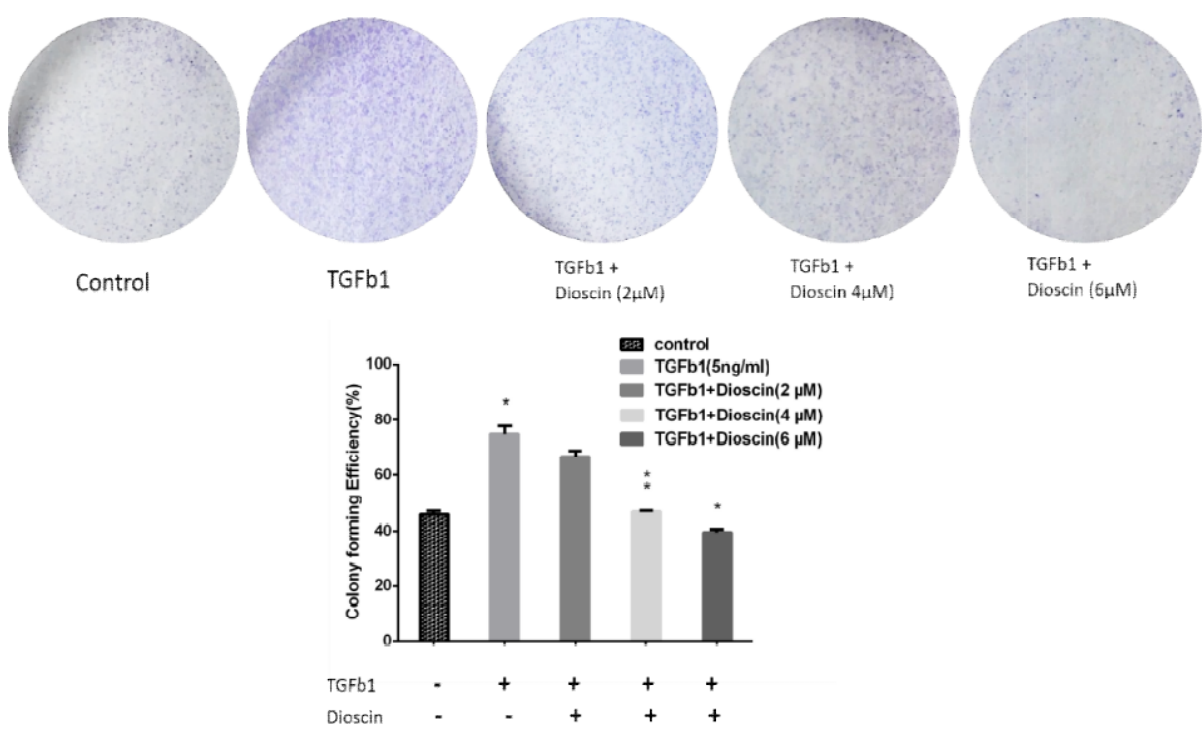

Figure 5: Invitro colony formation assay. Effect of Dioscin on MDA-MB-231 cells with TGF- $\beta 1$ stimulation. *p<0.05, $* * \mathbf{p}<0.001, * * * \mathbf{p}<0.001$, NS-Non-significant compared to control
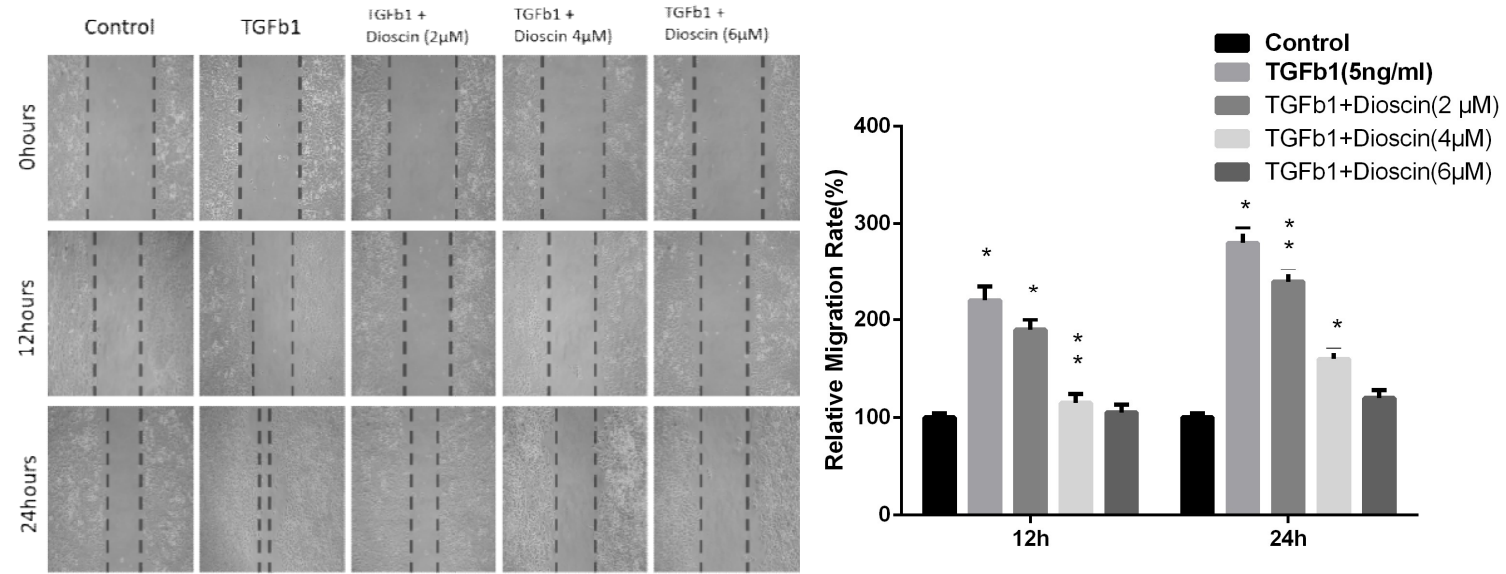

Figure 6: Wound healing assay. Effect of Dioscin on MCF7 cells with TGF-ß1 stimulation. Data expressed as mean \pm S.D. of three independent experiments. $* \mathbf{p}<0.05, * * \mathbf{p}<0.001, * * * \mathbf{p}<0.001$, NS-Non-significant compared to control
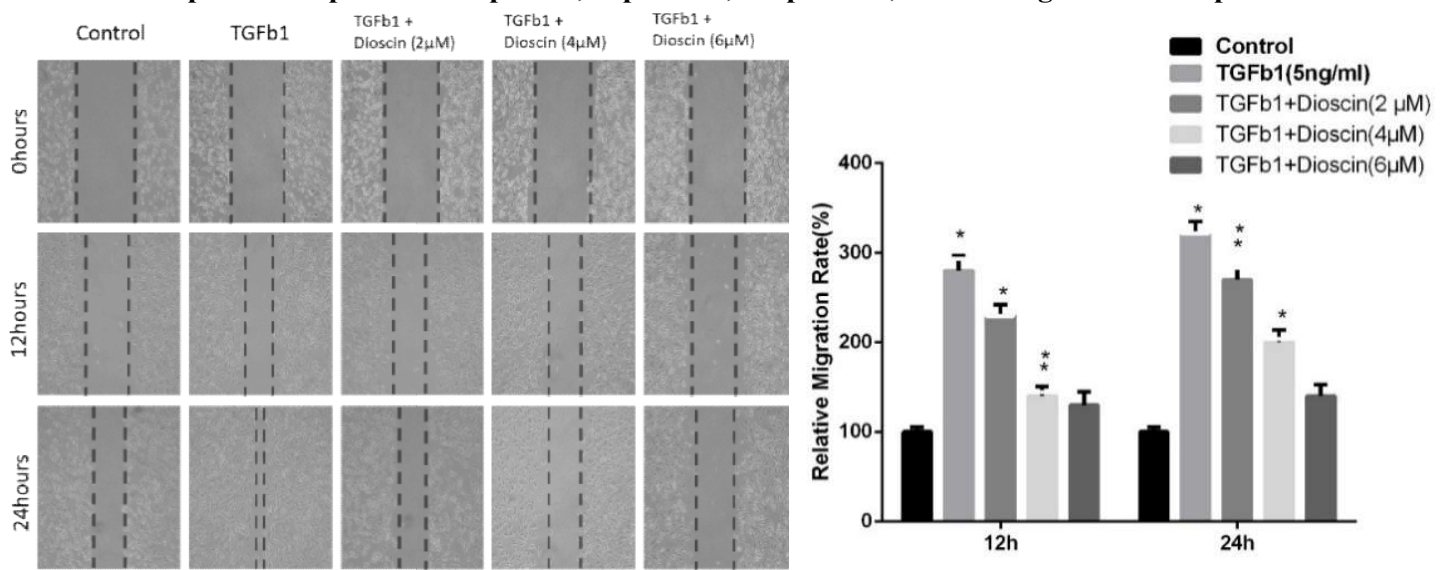

Figure 7: Wound healing assay. Effect of Dioscin on MDA-MB-231cells with TGF- $\beta 1$ stimulation. Data expressed as mean \pm S.D. of three independent experiments. ${ }^{*} p<0.05,{ }^{* *} p<0.001,{ }^{* * *} p<0.001$, NS-Non-significant compared to control 


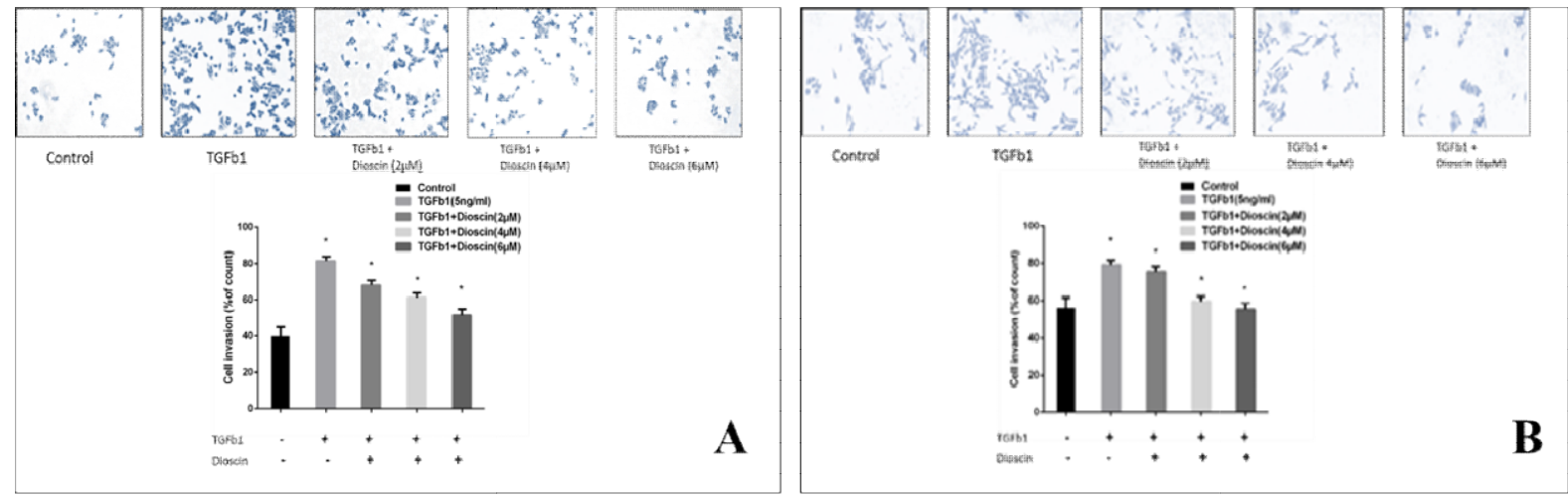

Figure 8: Transwell migration assay. Effect of Dioscin on MCF7 (A) and MDA-MB-231 (B); Cells treated with 5 ng/mL

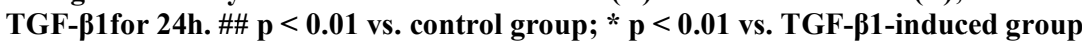
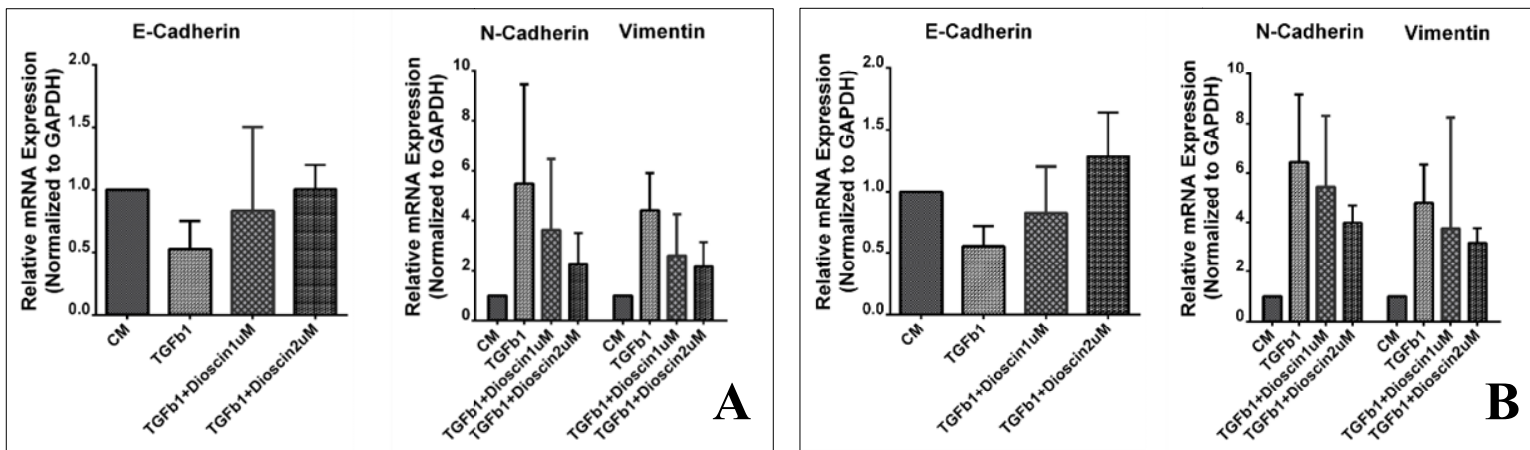

Figure 9: MCF7 (A) and MDA-MB-231 (B) were treated with TGF- $\beta 1$ (5 ng/ml, 24h) or with TGF- $\beta 1$ and Dioscin (1 and $2 \mu \mathrm{M}$ ), and the expression levels of indicated genes were analyzed by qRT-PCR. Fold change was calculated by $2-\Delta \Delta C T$ relative quantitative analysis. The data are expressed as mean \pm SD for triplicates

From this result, It is observed that the mRNA level of the epithelial marker, Ecadherin, up-regulated with the increasing concentration of Dioscin. However, the mesenchymal markers, $\mathrm{N}$-cadherin as well as vimentin decreased in a dose-dependent manner.

\section{DISCUSSION}

Importance of Dioscin effects on cancer cells has been rising, due to its anti-cancer activities, and it has been reported that Dioscin may be a possible candidate for cancer therapy $[4,10]$. MCF7 and MDAMB-231 cells are commonly used to study the biology of breast adenocarcinoma. In the present study, Dioscin inhibited the growth of breast cancer cells in a dose-dependent manner. Epithelial to Mesenchymal Transition (EMT) is a process of malignant transformation by the loss of epithelial cell polarity and the acquisition of an elongated mesenchymal morphology, associated with the disturbance of cell adhesion,increased cell migration, invasion and metastasis, and therapeutic resistance $[\mathbf{1 1}, \mathbf{1 2}]$. TGF- $\beta 1$ is commonly used to induce EMT in cancer cells. TGF- $\beta 1$ is an inducer of EMT in cancer cell and also an important growth-promoting 
factor. It induces EMT through smad and non-smad signaling pathways. When TGF- $\beta 1$ stimulation, in the canonical TGF- $\beta 1$ signaling pathway, Smad2 and Smad3 are phosphorylated, and then translocated to the nucleus, inducing the EMT. PI3K/AKT, JNK, p38 MAPK, and MAPK are phosphorylated and activated by TGF- $\beta 1$ in the non-Smad signaling pathway [13]. Transwell assay and Scratch assay are commonly used to evaluate EMT, and Dioscin suppressed the TGF- $\beta 1$-induced migration and invasion of Breast cancer cells. This finding supports the future development of Dioscin as a clinical agent in Breast cancer therapy. During EMT, epithelial cells lose their intracellular junctions, and they attain more mesenchymal properties, including increased expression of the mesenchymal markers N-cadherin and Vimentin, and EMT transcription factors Snail and Slug, that inhibit E-cadherin. It has reported that the loss of E-cadherin and high expression of Vimentin are significantly related with poor prognosis in numerous cancer [14]. In the present study, we observed that Dioscin upregulated the expression of E-cadherin and down-regulated the expression of Vimentin in EMT induced Breast cancer cells. Our findings demonstrated the anti-proliferation and anti-EMT activities of Dioscin on TGF$\beta 1$ stimulated Breast cancer cells.

\section{CONCLUSION}

Based on this result, Dioscin is a promising strategy that may prevent Breast cancer cells from additional malignant transformation. These findings may lead to further study on mechanism that involved in EMT suppression by Dioscin to develop novel therapeutic strategies.

\section{REFERENCES}

[1] Prusty, R. K., Begum, S., Patil, A., Naik, D. D., Pimple, S., \& Mishra, G. (2020). Knowledge of symptoms and risk factors of breast cancer among women: a community based study in a low socioeconomic area of Mumbai, India. BMC Women's Health, 20, 1-12.

[2] Malvia, S., Bagadi, S. A., Dubey, U. S., \& Saxena, S. (2017). Epidemiology of breast cancer in Indian women. Asia-Pacific Journal of Clinical Oncology, 13(4), 289-295.

[3] Valastyan, S., \& Weinberg, R. A. (2011). Tumor metastasis: molecular insights and evolving paradigms. Cell, 147(2), 275-292.

[4] Lim, W. C., Kim, H., Kim, Y. J., Choi, K. C., Lee, I. H., Lee, K. H., \& Ko, H. (2017). Dioscin suppresses TGF- $\beta 1$ induced epithelial-mesenchymal 
transition and suppresses A549 lung cancer migration and invasion. Bioorganic \& Medicinal Chemistry Letters, 27(15), 3342-3348.

[5] Lu, B., Yin, L., Xu, L., \& Peng, J. (2011). Application of proteomic and bioinformatic techniques for studying the hepatoprotective effect of Dioscin against CCl4-induced liver damage in mice. Planta medica, 77(05), 407-415.

[6] Sautour, M., Mitaine-Offer, A. C., Miyamoto, T., Dongmo, A., \& LacailleDubois, M. A. (2004). Antifungal steroid saponins from Dioscorea cayenensis. Planta medica, 70(1), 90-92.

[7] Wang, Y., Che, C. M., Chiu, J. F., \& He, Q. Y. (2007). Dioscin (saponin)-induced generation of reactive oxygen species through mitochondria dysfunction: a proteomic-based study. Journal of proteome research, 6(12), 4703-4710.

[8] Xu, X. H., Li, T., Fong, C. M. V., Chen, X., Chen, X. J., Wang, Y. T., \& Lu, J. J. (2016). Saponins from Chinese medicines as anticancer agents. Molecules, 21(10), 1326.

[9] Kasai, H., Allen, J. T., Mason, R. M., Kamimura, T., \& Zhang, Z. (2005). TGF- $\beta 1$ induces human alveolar epithelial to mesenchymal cell transition (EMT). Respiratory research, 6(1), 1-15.
[10] Tao, X., Yin, L., Xu, L., \& Peng, J. (2018). Dioscin: a diverse acting natural compound with therapeutic potential in metabolic diseases, cancer, inflammation and infections. Pharmacological research, 137, 259-269.

[11] Hanahan, D., \& Weinberg, R. A. (2011). Hallmarks of cancer: the next generation. Cell, 144(5), 646-674.

[12] Thiery, J. P., Acloque, H., Huang, R. Y., \& Nieto, M. A. (2009). Epithelialmesenchymal transitions in development and disease. Cell, 139(5), 871-890.

[13] Smith, A. L., Robin, T. P., \& Ford, H. L. (2012). Molecular pathways: targeting the TGF- $\beta$ pathway for cancer therapy. Clinical Cancer Research, 18(17), 45144521.

[14] Toiyama, Y., Yasuda, H., Saigusa, S., Tanaka, K., Inoue, Y., Goel, A., \& Kusunoki, M. (2013). Increased expression of Slug and Vimentin as novel predictive biomarkers for lymph node metastasis and poor prognosis in colorectal cancer. Carcinogenesis, 34(11), 2548-2557. 